\title{
АНАЛИЗ ЭФФЕКТИВНОСТИ ПРИМЕНЕНИЯ ВЯЗКОУПРУГОГО ПОВЕРХНОСТНО-АКТИВНОГО СОСТАВА НА МЕСТОРОЖДЕНИЯХ ЗАПАДНОЙ СИБИРИ
}

\author{
Гумерова Гульнур Рашитовна', \\ gumgul@yandex.ru \\ Яркеева Наталья Расатовна', \\ yarkeevan@yandex.ru \\ 1 Уфимский государственный нефтяной технический университет,
Россия, 450062, г. Уфа, ул. Космонавтов, 1.
}

Актуальность исследования определена тем, что современное состояние многих нефтяных месторождений характеризуется массовым их вступлением в позднюю стадию разработки. Скважинная продукция сопровождается увеличением обводненности скважин при сохранении достаточного количества остаточных извлекаемых запасов нефти. При воздействии на пласт заводнением не все пропластки вовлекаются в разработку. Причинами являются неоднородность пласта, как по вертикали, так и по латерали, высокое соотношение вязкостей добываемой нефти и нагнетаемой воды. При этом процессы в пласте также сопровождаются преждевременным прорывом воды и, следовательно, снижением коэффициента нефтеотдачи. В связи с этим многие нефтяные компании уделяют большое внимание использованию методов регулирования фильтрационных потоков. Одной из таких эффективных технологий, с потокоотклоняющим действием, является применение сшитых полимерных составов. Их преимущества: более высокая вязкость раствора, чем у обычного полимера, создание высокого фактора остаточного сопротивления и способность проникать на более дальние расстояния от ствола нагнетательной скважины.

Цель: оценка технологической эффективности от закачки вязкоупругого поверхностно-активного состава на одном из месторождений Западной Сибири.

объектом исследования является участок пласта с невовлекаемыми в разработку запасами и высокой обводненностью. Методы исследования основаны на анализе работы участка проведения обработки, построении карт, оценки запасов. Результаты. Расчитана эффективность обработки нагнетательной скважины на основе интегральной характеристики вытеснения и результатов промысловых геофизических исследований. Выявлено, что технология использования вязкоупругого поверхностно-активного состава успешно была применена и может быть в дальнейшем использована на других месторождениях Западной Сибири.

\section{Ключевые слова:}

Выравнивание профиля приемистости, сшитый полимерный состав, полиакриламид, сшиватель, неоднородность пласта.

\section{Введение}

В настоящее время осуществляются как «классические» технологии применения сшитых полимерных составов (СПС) (раствор полиакриламида со сшивателем), так и различные их модификации. Выбор марок полимеров определяется особенностями технологий их применения, геолого-физическими условиями залегания пластов, свойствами растворителя, сшивающего агента - все это уточняется для условий каждого объекта [1-3].

При заводнении продуктивных пластов одной из эффективных является технология ВУПАС (вязкоупругий поверхностно-активный состав) на основе полиакриламида (марок Seurvey R1, DP 9-8177, FP-107, AN-132, Praestrol) и комплексных поверхностно-активных веществ (Катол-22А, Нефтенол-К, Нефтенол-ВВД). При этом устойчивый гель образуется непосредственно в пласте. Для образования СПС используется сшивающий агент - ацетат хрома, который позволяет изменять диапазон времени гелеобразования в различных пределах и эффективно направлять фильтрационные потоки. Известно, что по месторождениям Мегионской группы наибольшее снижение попутно добываемой воды и самые продолжительные эффекты от обработок наблюдаются при использовании технологии ВУПАС, в том числе на участках скважин с трещиной ГРП (гидравлического разрыва пласта) [4]. Также стоит заметить, что именно эта технология, по сравнению с ГОС (гелеобразующий состав), ООС (осадкообразующий состав), наиболее эффективна в низкопроницаемых зонах пласта (проницаемость менее 0,2 Д), из-за больших размеров молекул раствора. Это приводит к кольматации призабойной зоны пласта и механическому разрушению молекул полимера.

При закачке стандартного СПС снижение проницаемости в низкопроницаемых пропластках незначительно, так как гель в большей степени воздействует на высокопроницаемые пропластки [5]. При использовании технологии ВУПАС поверхностно-активное вещество (ПАВ) воздействует в большей степени на низкопроницаемые интервалы пласта. За счет гидрофобизации пород после закачки ПАВ проницаемость по воде увеличивается значительно. Следовательно, повышается эффективность перераспределения потоков воды [6-10].

\section{Основная часть}

Применение технологии ВУПАС осуществляется на Аганском, Ватинском, Западно-Усть-Балык- 
ском, Северо-Покурском, Мегионском, Узунском месторождениях, в основном в неоднородных пластах $\mathrm{AB}_{1}^{3}, \mathrm{AB}_{2}, \mathrm{BB}_{10}$. Анализ применения ВУПАС проведем на примере одного из этих месторождений. В разрезе слагающих пород многопластового месторождения выделены несколько продуктивных объектов: пласты группы АВ нижнеалымской подсвиты и ванденской, БВ - мегионской свиты нижнего мела, ЮВ - васюганской свиты верхней юры.

Пласт $\mathrm{AB}_{1}^{3}$ представлен сложно построенной толщей пород, которая именуется как «рябчиковые». Для таких залежей характерно отсутствие общей закономерности изменения коэффициента нефтенасыщенности по высоте залежи, отмечающейся для всех залежей Западной Сибири с обычной литолого-коллекторской характеристикой.

В связи с этим в пределах пласта $\mathrm{AB}_{1}^{3}$ выделено лишь три нефтенасыщенных залежи, несмотря на то, что пласт имеет достаточно пологие формы залегания и площадное распространение с отсутствием участков полной глинизации пород-коллекторов.

Промышленная эксплуатация объекта $\mathrm{AB}_{1}^{3}$ в 1997-2007 гг. осуществлялась на естественном режиме. С августа 2008 г. начали вводить нагнетательные скважины для организации системы поддержания пластового давления. Объект разрабатывается системой горизонтальных добывающих скважин с расстоянием между скважинами 400 м, обеспечивающим оптимальную выработку запасов.

В июне 2015 г., с целью повышения нефтеотдачи пластов, была проведена обработка (рис. 1) нагнетательной скважины 1 на объекте $\mathrm{AB}_{1}^{3}$ с применением технологии ВУПАС.

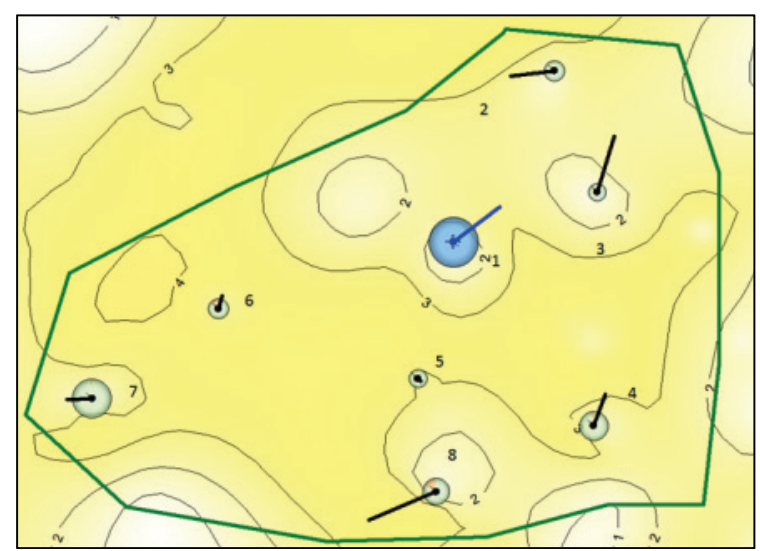

Pис.1. Обрабатываемый участок скважин на карте остаточных нефтенасыщенных толшин

Fig. 1. Processed section of wells on the map of residual oil-satura ted thicknesses

Участок воздействия характеризуется большим темпом обводнения добываемой продукции, по сравнению со средней величиной по пласту, наличием остаточных извлекаемых запасов, повышенной послойной неоднородностью и расчлененностью. Перечисленные параметры благоприятствуют применению СПС [11-17]. Также скважины выбранного участка - 1, 2, 4, 7, 8 - характеризуются искусственной трещиноватостью после проведения ГРП.

По выбранному участку были оценены остаточные запасы по карте остаточных нефтенасыщенных толщин и накопленной добыче. Также на основе характеристики вытеснения по истории добычи нефти и жидкости построена зависимость водо-нефтяного фактора от накопленной добычи нефти $\left(\mathrm{BH} \Phi=f\left(Q_{\mathrm{H}}\right)\right)$, по которой определяют оста-

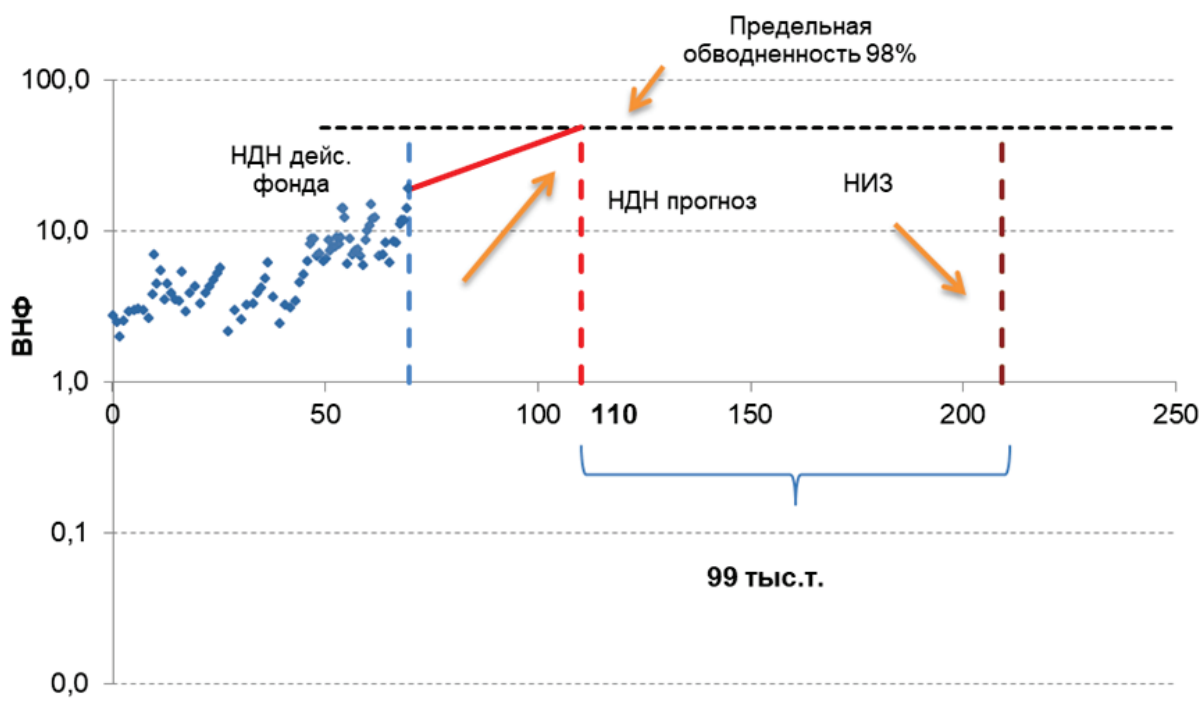

Накопленная добыча нефти, тыс.т

Pис. 2. График выработки запасов

Fig. 2. Plot of reserve recovery 
точные извлекаемые запасы и характер выработки запасов (рис. 2) [18].

На рис. 2 строится линия тренда до рентабельной обводненности на прямолинейном участке добычи, соответствующая постоянному фонду скважин, и определяется прогнозная накопленная добыча нефти, которую можно извлечь при существующей системе разработки. Видно, что прогнозная накопленная добыча нефти составит примерно 110 тыс. т, т. е. примерно 99 тыс. т нефти не будет вовлечено в разработку.

Дебиты нефти и жидкости, а также обводненность данного участка на июнь 2015 г., перед выравниванием профиля приемистости (ВПП), приведены в таблице.

Таблица. Показатели разработки реагирующих скважин до ВПП

Table. $\quad$ Parameters of producing oil wells development before the equalization profile $\log (E P L)$

\begin{tabular}{|c|c|c|c|c|}
\hline $\begin{array}{c}\text { Тип } \\
\text { скважины } \\
\text { Well type }\end{array}$ & $\begin{array}{l}\text { № скв. } \\
\text { Well no. }\end{array}$ & $\begin{array}{c}\text { Дебит нефти, } \\
\text { т/сут } \\
\text { Oil-production } \\
\text { rate, ton/day }\end{array}$ & $\begin{array}{c}\text { Дебит жидкости, } \\
\mathrm{M}^{3} / \text { сут } \\
\text { Liquid rate, } \\
\text { cubic meter/day }\end{array}$ & $\begin{array}{c}\text { Обводнен- } \\
\text { ность, \% } \\
\text { Water cut, } \\
\text { p.c }\end{array}$ \\
\hline \multirow{7}{*}{ 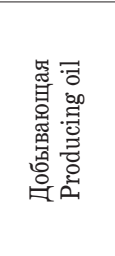 } & 2 & 0,2 & 9 & 97 \\
\hline & 3 & 1,08 & 21 & 94 \\
\hline & 4 & 2,48 & 48 & 94 \\
\hline & 5 & 0,74 & 12 & 93 \\
\hline & 6 & 2,7 & 25 & 85 \\
\hline & 7 & 1,46 & 85 & 98 \\
\hline & 8 & 9,2 & 43 & 75 \\
\hline
\end{tabular}

Из таблицы видно, что скважины 2 и 7 достигли предельного обводнения $98 \%$, в скважинах 3-5 обводненность в пределах $94 \%$, а в 6 и 8 - самая низкая в пределах участка, 85 и $75 \%$ соответственно.

До ВПП с начала 2015 г. резко упали дебиты нефти, обводненность при этом увеличилась. Связано это с перекрытием нефтенасыщенных пропластков, что привело к поступлению в скважины воды из более высокопроницаемых участков пласта.

В июне 2015 г. было закачено $150 \mathrm{~m}^{3}$ раствора по технологии ВУПАС, динамика основных показателей разработки участка, после воздействия, показана на рис. 3.

Из рис. 3 видно, что добывающие скважины среагировали на обработку скв. 1 в сентябре 2015. Как результат - снижение и стабилизация обводнения на уровне $97 \%$. Это свидетельствует о положительном эффекте от обработки.

Также эффективность проведенной закачки в пласт раствора полиакриламида, сшивателя и комплексного ПАВ подтверждена промысловыми геофизическими исследованиями - при определении профиля поглощения водонагнетательной скважины до и после обработки на скв. 1. В ходе работы была выполнена запись механической расходометрии в интервале детальных исследований на режиме закачки при $P_{\text {зак }}=147$ атм (рис. 4).

По комплексу проведенных исследований отмечается уход закачиваемой жидкости в проектный перфорированный интервал пласта $\mathrm{AB}_{1}^{3}$. Вид-

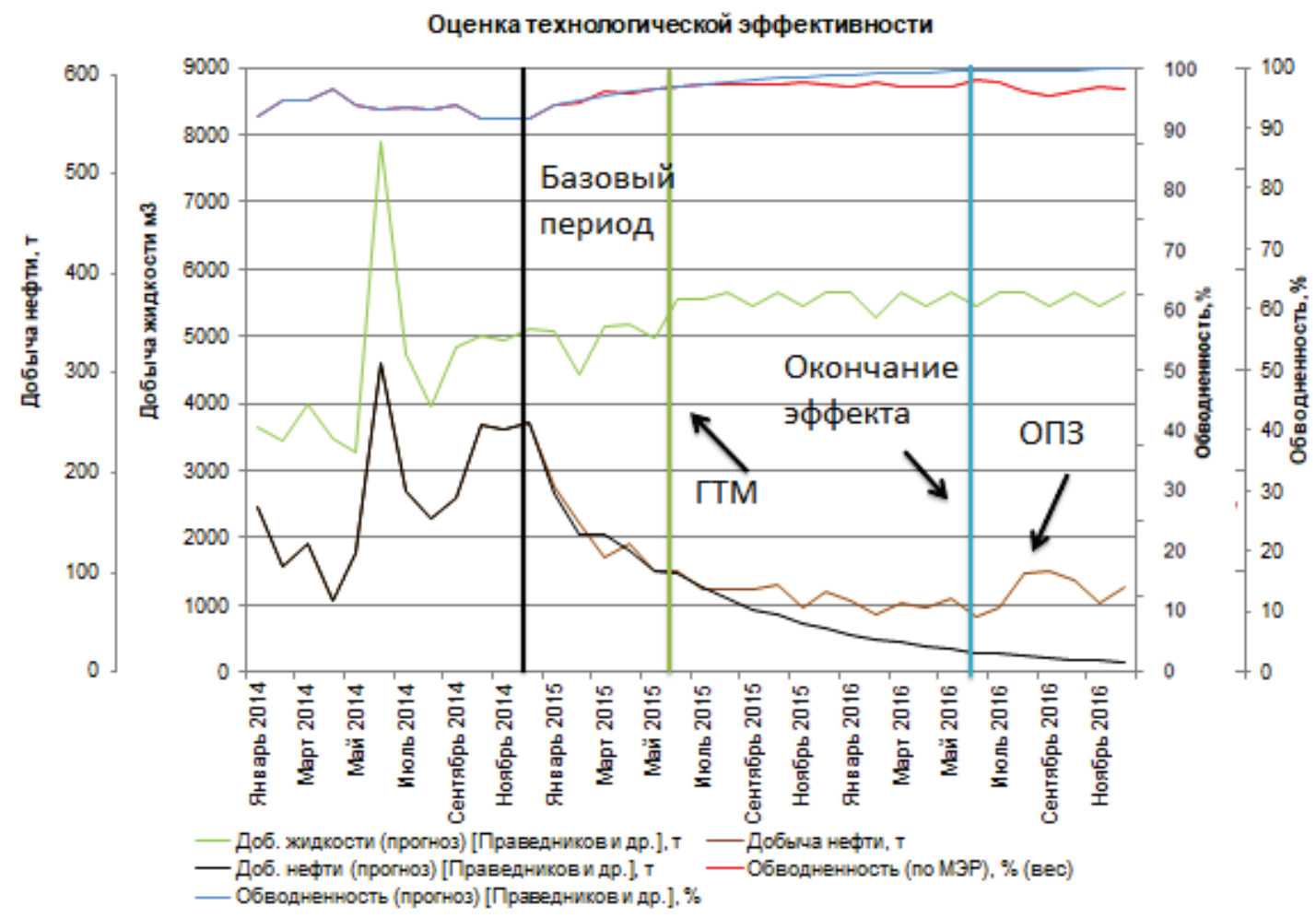

Pис. 3. Основные показатели разработки участка

Fig. 3. Main parameters of reservoir development 
но, что интервалы пласта на глубинах 1818-1819, 1819,8-1820,6 м отключились, а на глубинах $1820,6-1821,8$ и $1822,8-1823,6$ м расход жидкости увеличился с 57 до $65 \%$ и с 11 до $26 \%$ соответственно. Также можно отметить, что после ВПП в работу включились интервалы пласта на глубинах 1823,6-1824,2 и 1826-1827 м, что привело $к$ увеличению добычи нефти из этих пропластков. При этом также можно отметить, что заколонные перетоки отсутствуют, а эксплуатационная колонна и колонна насосно-компрессорной трубы в интервале исследований герметичны.
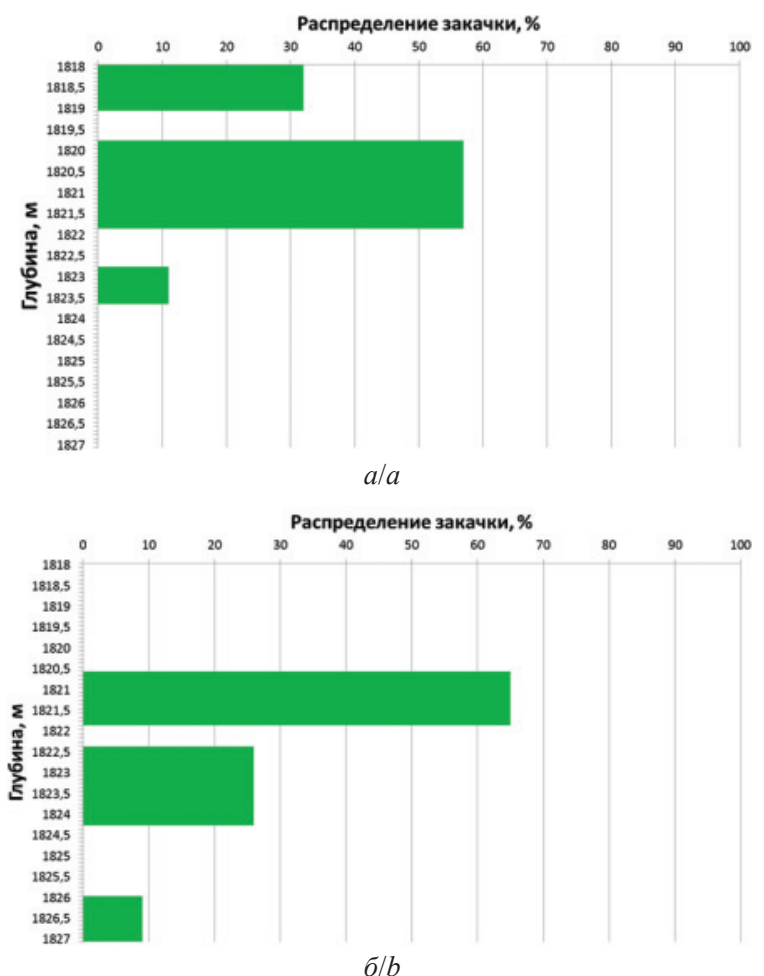

Рис.4. Результаты исследований профиля поглощения скв. 1: а) до ВПП; б) после ВПП

Fig. 4. Results of research of the well № 1 absorption profile: a) before EPL; b) after EPL

Расчет эффективности геолого-технического мероприятия проводился по характеристикам вытеснения - по интегральной модели с помощью метода Праведникова и др.:

$$
Q_{\hat{1}}=a+b \cdot Q_{æ}^{1-1 / c},
$$

где $Q_{\text {н }}$ - накопленная добыча нефти; $Q_{ж}-$ накопленная добыча жидкости; $a, b, c$ - параметрические коэффициенты.

Преимуществом интегрального метода (когда рассматриваются суммарные показатели всех скважин участка воздействия) является возможность учета интерференции скважин и уменьшение влияния погрешностей замеров. Изначально для определения расчетов одним из методов на пяти моделях были построены кривые характеристик вытеснения. Наибольшим коэффициентом корреляции по построенным зависимостям характеризуется модель Праведникова и др.

За базовый период (динамика технологических показателей без применения технологии) было выбрано семь месяцев, произведена математическая обработка фактических промысловых данных разработки (рис. 3) [19, 20].

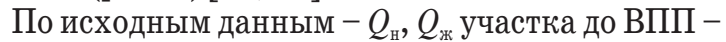
была построена зависимость, по которой определена линия тренда, уравнение зависимости и параметрические коэффициенты. При экстраполировании результатов, для прогноза эффекта от ВПП, был принят постоянный отбор жидкости, определен базовый тренд поведения дебита нефти. Эффективность метода увеличения нефтеотдачи была определена путем сравнения фактической и прогнозной прямой [21-25]. Дополнительная добыча нефти при этом на 01.06.2016 г. составила 588,66 т, эффект от ВПП составил 10 месяцев с учетом того, что реакция добывающих скважин произошла через три месяца. При расчете технологической эффективности ВПП скважины 2,6 и 8 были исключены, так как с декабря 2015 г. скв. 2 и 6 находятся в бездействии, а в скв. 8 провели обработку предзабойной зоны.

\section{Выводы}

Полученные результаты позволяют говорить об успешности применения технологии ВУПАС (модифицированного СПС): снижение отборов добываемой воды, увеличение добычи нефти и коэффициента вытеснения неоднородных терригенных коллекторов, которые характеризуются высокой обводненностью продукции, неравномерной выработкой запасов и значительными остаточными извлекаемыми запасами. 


\section{СПИСОК ЛИТЕРАТУРЫ}

1. Земцов Ю.В., Баранов В.А., Гордеев А.О. Обзор физико-химических МУН, применяемых в Западной Сибири, и эффективности их использования в различных геолого-физических условиях // Нефть. Газ. Новации. - 2015. - № 7. - С. 11-12.

2. Химченко П.В. Алгоритм внедрения технологии полимерного заводнения от лаборатории до реализации на новых и выработанных месторождениях // Нефть. Газ. Новации. - 2017. № 8. - С. 30-43.

3. Реализация нового подхода к размещению гелевых составов в обводненных высокопроницаемых изолированных пластах / Р.И. Магзянов, Т.А. Исмагилов, В.П. Захаров, С.А. Вежнин, С.В. Захаров // Нефтяное хозяйство. - 2011. - № 6. - С. 25-29.

4. Жуков Р.Ю. Обоснование применения технологий по выравниванию профиля приемистости на поздней стадии разработки нефтяных месторождений (на примере месторождений Среднего Приобья): автореф. дис.... канд. техн. наук. - М., 2013. $24 \mathrm{c.}$

5. Полимерное заводнение на опытном участке Самотлорского месторождения. Обоснование эксперимента и предварительные результаты / В.В. Литвин, М.В. Самойлов, С.А. Власов, Я.М. Каган, Б.М. Кудряшов // Бурение и нефть. - 2009. № 3, 4. - C. 52-54.

6. Kang X.D., Zhang J. Offshore Heavy Oil Polymer Flooding Test in JZW Area // SPE Heavy Oil Conference. - Canada, Calgary, Alberta, 2013. - P. 1-8.

7. Optimized polymer enhanced foam flooding for ordinary heavy oil reservoir after cross-linked polymer flooding / Chen Sun, Jian Hou, Guangming Pan, Zhizeng Xia //Journal of Petroleum Exploration and Production Technology. - 2016. - V. 6. - № 4. P. 777-785.

8. Changhong Gao, Jing Shi, Fangjian Zhao. Successful polymer flooding and surfactant-polymer flooding projects at Shengli Oilfield from 1992 to 2012 // Journal of Petroleum Exploration and Production Technology. - 2014. - V. 4. - № 1. - P. 1-8.

9. Sheng J.J., Leonhardt B., Azri N. Status of polymer-flooding technology // Journal of Canadian Petroleum Technology. 2015. - V. 54. - P. 116-126.

10. Injection parameters optimization of cross-linked polymer microspheres and polymer composite flooding system / J. Yang, X. Xie, J. Zhang, X. Zheng, Z. Wei // Petroleum Exploration and Development. - 2014. - V. 41. - № 6. - P. 794-797.

11. Fan Liu, Hanqiao Jiang, Xuelin Wu. Improved Approach to Evaluating the Hydrodynamic Performance of Polymers in the Early Stage of Polymer Flooding // Chemistry and Technology of Fuels and Oils. - 2016. - V. 52. - № 1. - P. 95-102.

12. Guijiang Wang Xiaoling, Yi Xin Fang Feng Baoguo, Jing Jian Ouyang. Synthesis and study of a new copolymer for polymer flooding in high-temperature, high-salinity reservoirs // Chemistry and Technology of Fuels and Oils. - 2012. - V. 48. - № 1. P. 112-119.

13. Experimental study on the mechanism of enhancing oil recovery by polymer - surfactant binary flooding / Weidong Liu, Litao Luo, Guangzhi Liao, Luo Zuo, Yunyun Wei, Wei Jiang // Petroleum Exploration and Development. - 2017. - V. 44. - № 4. P. 636-643.
14. Hadi Saboorian-Jooybari, Morteza Dejam, Zhangxin Chen. Heavy oil polymer flooding from laboratory core floods to pilot tests and field applications: Half-century studies // Journal of Petroleum Science and Engineering. - 2016. - V.14. - P. 85-100.

15. Опыт применения гелеобразующей композиции «Геопан-М» на месторождениях ОАО «Удмуртнефть» / Д.О. Перевощиков, А.М. Белых, Е.В. Вакатова, Т.А. Исмагилов, И.М. Ганиев // Инженерная практика. - 2015. - № 6-7. - С. 34-37.

16. Обоснование и разработка технологии полимерного заводнения в слоисто-неоднородном пласте для повышения эффективности извлечения запасов / К.В. Стрижнев, А.А. Громан, М.И. Кузьмин, Е.А. Румянцева // Нефтяное хозяйство. 2011. - № 12. - С. 34-37.

17. Гумерова Г.Р., Яркеева Н.Р. Технология применения сшитых полимерных составов // Нефтегазовое дело: электрон. науч. журн. - 2017. - № 2. - С. 63-79.

18. Исследование выработки запасов нефти из послойно неоднородного по проницаемости пласта с применением полимерного заводнения / И.В. Владимиров, М.Н. Шаймарданов, Е.В. Задорожный, С.И. Хазов, Р.А. Гнилицкий // Нефтепромысловое дело. - 2012. - № 9. - С. 5-12.

19. Толстоногов А.А. Оценка эффективности геолого-технических мероприятий в области нефтедобычи // Фундаментальные исследования. - 2014. - № 11-1. - С. 150-154.

20. Нуртдинов А.Р., Яркеева Н.Р. Применение циклического заводнения как МУН и анализ его эффективности на примере месторождения Западной Сибири // Нефть и газ-2017: сб. тез. 71-й Междунар. Молодежной науч. конф. - М., 18-20 апреля 2017. - М.: РГУ нефти и газа (НИУ) имени И.М. Губкина, 2017. - T. 1. - С. 317.

21. Обоснование выбора объекта под полимерное воздействие на примере пластов $\mathrm{AB} 1(3)$ и AB2-3 Самотлорского месторождения / Н.И. Хисамутдинов, М.Н. Шаймарданов, В.В. Литвин, С.И. Хазов // Нефтепромысловое дело. - 2012. - № 11. С. $54-59$.

22. Телков В.П., Ким С.В., Мостаджеран М.Г. Повышение эффективности вытеснения высоковязких нефтей полимерными растворами // Проблемы геологии и освоения недр: труды XXI Международного симпозиума имени академика М.А. Усова студентов и молодых ученых, посвященного 130-летию со дня рождения профессора М.И. Кучина. - Томск, 3-7 апреля 2017. - Томск: Изд-во ТПУ, 2017. - Т. 2. - С. 148-150.

23. Saboorian-Jooybari H., Dejam M., Chen, Z. Half-Century of Heavy Oil Polymer Flooding from Laboratory Core Floods to Pilot Tests and Field Applications / SPE-174402-MS, SPE Canada Heavy Oil Technical Conference. - Calgary, Alberta, Canada, 12-14 June 2015. - P. 1-26.

24. Разработка состава для технологии ПАВ-полимерного заводнения применительно к условиям месторождения Белый Тигр / Л.А. Магадова, В.Б. Губанов, Фан Ву Ань, К.А. Довгий // Промышленный сервис. - 2016. - № 3. - С. 21-25.

25. Алтунина Л.К., Кувшинов В.А. Увеличения нефтеотдачи месторождений на поздней стадии разработки физико-химическими методами // Нефтепромысловая химия. - 2013. № 8. - С. 18-25.

Поступила 20.04.2018 г.

\section{Информация об авторах}

Гумерова Г.P., студент кафедры разработки и эксплуатации нефтяных и газонефтяных месторождений Уфимского государственного нефтяного технического университета.

Яркеева Н.P., кандидат технических наук, доцент кафедры разработки и эксплуатации нефтяных и газонефтяных месторождений Уфимского государственного нефтяного технического университета. 


\title{
ANALYSIS OF THE EFFICIENCY OF APPLYING VISCOUS-ELASTIC SURFACE-ACTIVE COMPOSITION ON THE FIELDS OF WESTERN SIBERIA
}

\author{
Gulnur R. Gumerova', \\ gumgul@yandex.ru \\ Natalya R. Yarkeeva', \\ yarkeevan@yandex.ru \\ 1 Ufa State Petroleum Technological University, \\ 1, Kosmonavtov street, Ufa, 450062, Russia.
}

The relevance of the research consists in the fact that the current state of many oil fields is characterized by their mass entry into the late stage of development, well production of which is accompanied by increase in water cut of wells while maintaining a sufficient number of residual recoverable oil reserves. Not all streaks are involved in development when exposed to reservoir flooding. The reasons are the heterogeneity of formation, both vertically and laterally, high ratio of the viscosity of the extracted oil and pumped water. At the same time, the processes in the reservoir are accompanied as well by a premature breakthrough of water and, consequently, decrease in the oil recovery coefficient. In this regard, many oil companies pay great attention to the use of filtration flows regulating methods. One of the most effective technologies with a flow-reducing effect is the use of cross-linked polymer compounds. Their advantage is a higher viscosity of a solution than that of a conventional polymer, the creation of a high residual resistance factor and the ability to penetrate deeper from water-injection well.

The aim of the study is to assess the technological effectiveness injection of viscous-elastic surface-active composition at one of the fields in Western Siberia.

Object of research is a section of the reservoir, with uninvolved oil reserves and high water cut.

The research methods include the analysis of the processing site, mapping, inventory estimation.

Results. The authors have calculated the efficiency of processing the injection well based on the integrated characteristic of displacement and by the results of field geophysical researches; and revealed that the technology of using viscous-elastic surface-active structure was effectively applied and can be used further on other fields of Western Siberia.

Key words:

Alignment of injectivity profile, crosslinked polymer structure, polyacrylamide, stapler, reservoir heterogeneity.

\section{REFERENCES}

1. Zemtsov Yu.V., Baranov V.A., Gordeev A.0. Obzor fiziko-khimicheskikh MUN, primenyaemykh v Zapadnoy Sibiri, i effektivnosti ikh ispolzovaniya v razlichnykh geologo-fizicheskikh usloviyakh [Overview of the physicochemical MUN used in Western Siberia, and the effectiveness of their use in various geological and physical conditions]. Neft. Gaz. Novatsii, 2015, no. 7, pp. 11-12.

2. Khimchenko P.V. Algorithm in Using Polymer Flooding Procedure from Lab to Field Application on Green-fields and Brownfields. Neft. Gaz. Novatsii, 2017, no. 8, pp. 30-43. In Rus.

3. Magzyanov R.I., Ismagilov T.A., Zakharov V.P., Vezhnin S.A., Zakharov S.V. Realization of new method of gel placement in watered high permeable formation. Neftyanoe khozyaystvo, 2011, no. 6, pp. 25-29. In Rus.

4. Zhukov R.Yu. Obosnovanie primeneniya tekhnologiy po vyravnivaniyu profilya priemistosti na pozdney stadii razrabotki neftyanykh mestorozhdeniy (na primere mestorozhdeniy Srednego Priobya). Avtoreferat Kand. nauk. [Substantiation of application of technologies for equalizing the injectivity profile at the late stage of development of oil fields. Cand. Dis. Abstract]. Moscow, 2013. $24 \mathrm{p}$.

5. Litvin V.V., Samoylov M.V., Vlasov S.A., Kagan Ya.M., Kudryashov B.M. Polimernoe zavodnenie na opytnom uchastke Samotlorskogo mestorozhdeniya. Obosnovanie eksperimenta i predvaritelnye rezultaty [Polymer flooding in the pilot plot of the Samotlor field. Justification of the experiment and preliminary results]. Burenie i neft, 2009, no. 3, 4, pp. 52-54.

6. Kang X.D., Zhang J. Offshore Heavy Oil Polymer Flooding Test in JZW Area. SPE Heavy Oil Conference. Canada, Calgary, Alberta, 2013. pp. 1-8.

7. Chen Sun, Jian Hou, Guangming Pan, Zhizeng Xia. Optimized polymer enhanced foam flooding for ordinary heavy oil reservoir af- ter cross-linked polymer flooding. Journal of Petroleum Exploration and Production Technology, 2016, vol. 6, no. 4, pp. 777-785.

8. Changhong Gao, Jing Shi, Fangjian Zhao. Successful polymer flooding and surfactant-polymer flooding projects at Shengli Oilfield from 1992 to 2012. Journal of Petroleum Exploration and Production Technology, 2014, vol. 4, no. 1, pp. 1-8.

9. Sheng J.J., Leonhardt B., Azri N. Status of polymer-flooding technology. Journal of Canadian Petroleum Technology, 2015, vol. 54, pp. 116-126.

10. Yang J., Xie X., Zhang J., Zheng X., Wei Z. Injection parameters optimization of cross-linked polymer microspheres and polymer composite flooding system. Petroleum Exploration and Development, 2014, vol. 41, no. 6, pp. 794-797.

11. Fan Liu, Hanqiao Jiang, Xuelin Wu. Improved Approach to Evaluating the Hydrodynamic Performance of Polymers in the Early Stage of Polymer Flooding. Chemistry and Technology of Fuels and Oils, 2016, vol. 52, no. 1, pp. 95-102.

12. Guijiang Wang Xiaoling, Yi Xin Fang Feng Baoguo, Jing Jian Ouyang. Synthesis and study of a new copolymer for polymer flooding in high-temperature, high-salinity reservoirs. Chemistry and Technology of Fuels and Oils, 2012, vol. 48, no. 1, pp. 112-119.

13. Weidong Liu, Litao Luo, Guangzhi Liao, Luo Zuo, Yunyun Wei, Wei Jiang. Experimental study on the mechanism of enhancing oil recovery by polymer - surfactant binary flooding. Petroleum Exploration and Development, 2017, vol. 44, no. 4, pp. 636-643.

14. Saboorian-Jooybari H., Dejam M., Chen Zh. Heavy oil polymer flooding from laboratory core floods to pilot tests and field applications: Half-century studies. Journal of Petroleum Science and Engineering, 2016, vol. 14, pp. 85-100.

15. Perevoshhchikov D.0., Belykh A.M., Vakatova E.V., Ismagilov T.A., Ganiev I.M. Opyt primeneniya geleobrazuyushchey 
kompozitsii «Geopan-M» na mestorozhdeniyakh $0 \mathrm{A0}$ «Udmurtneft» [Experience of using the gel-forming composition «Geopan-

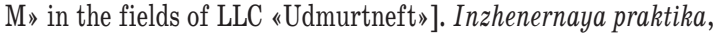
2015. no. 6-7, pp. 34-37.

16. Strizhnev K.V., Groman A.A., Kuzmin M.I., Rumyantseva E.A. Substantiation and development of polymer flooding technology in heterogeneous stratum for increasing the efficiency of extraction. Neftyanoe hozyaystvo, 2011, no. 12, pp. 34-37. In Rus.

17. Gumerova G.R., Yarkeeva N.R. Technology of application of crosslinked polymeric compositions. Neftegazovoe delo: ehlektron. nauch.Zhurn, 2017, no. 2, pp. 63-79. In Rus. Available at: http://ogbus.ru/files/ogbus/issues/2_2017/ogbus_2_2017 p63-79_GumerovaGR_ru.pdf (accessed 15 April 2018).

18. Vladimirov I.V., Shaymardanov M.N., Zadorozhny E.V., Khazov S.I., Gnilitsky R.A. Issledovanie vyrabotki zapasov nefti iz posloyno neodnorodnogo po pronitsaemosti plasta s primeneniem polimernogo zavodneniya [Investigation of development of oil reserves from layers of a reservoir heterogeneous in permeability using polymer flooding]. Neftepromyslovoe delo, 2012, no. 9, pp. $5-12$.

19. Tolstonogov A.A. Evaluation of geological and engineering activities in oil. Fundamentalnye issledovaniya, 2014, no. 11, pp. 150-154. In Rus.

20. Nurtdinov A.R., Yarkeeva N.R. Primenenie tsiklicheskogo zavodneniya kak MUN i analiz ego effektivnosti na primere mestorozhdeniya Zapadnoy Sibiri [Application of cyclic waterflooding as an EOR and analysis of its efficiency on the example of the West Siberian oil field]. Neft i gaz-2017: sb. tez.71-y Mezhdunar. Molodezhnoy nauch. konf [Oil and gas-2017: collection of articles. $71^{\text {th }}$ International Youth Scientific Conference]. Moscow, April 18-20, 2017. Moscow, the Russian State University of Oil and Gas (NIU), 2017. $317 \mathrm{p}$.
21. Khisamutdinov N.I., Shaymardanov M.N., Litvin V.V., Khazov S.I. Substantiation of an object selection to be subject to polymer effect with the example of AB1(3) and AB2-3 formations of Samotlor oil field. Neftepromyslovoe delo, 2012, no. 11, pp. 54-59. In Rus.

22. Telkov V.P., Kim S.V., Mostadzheran M.G. Povyshenie effektivnosti vytesneniya vysokovyazkikh neftey polimernymi rastvorami [Improving the efficiency of extrusion of highly viscous oils with polymer solutions]. Problemy geologii i osvoeniya nedr: trudy XXI Mezhdunarodnogo simpoziuma imeni akademika M.A. Usova studentov i molodykh uchenykh, posvyashchennogo 130-letiyu so dnya rozhdeniya professora M.I. Kuchina [Problems of geology and subsoil development: works of the XXI International Symposium named after academician M.A. Usov students and young scientists dedicated to the $130^{\text {th }}$ anniversary of the birth of Professor M.I. Kuchin]. Tomsk, TPU Publ. house, 2017. Vol. 2, pp. $148-150$.

23. Saboorian-Jooybari H., Dejam M., Chen Z. Half-Century of Heavy Oil Polymer Flooding from Laboratory Core Floods to Pilot Tests and Field Applications. SPE-174402-MS, SPE Canada Heavy Oil Technical Conference. Calgary, Alberta, Canada, 12-14 June 2015. pp. 1-26.

24. Magadova L.A., Gubanov V.B., Fan Vu An, Dovgij K.A. Composition development for surfactant-polymer flooding technology related to white tiger oilfield conditions. Promyshlenny servis, 2016, no. 3, pp. 21-25. In Rus.

25. Altunina L.K., Kuvshinov V.A. Uvelicheniya nefteotdachi mestorozhdeniy na pozdney stadii razrabotki fiziko-khimicheskimi metodami [Increased oil recovery deposits at a late stage of development by physicochemical by methods]. Neftepromyslovaya khimiya, 2013, no. 8, pp. 18-25.

\section{Information about the authors}

Gulnur R. Gumerova, student, Ufa State Petroleum Technological University.

Natalya R. Yarkeeva, Dr. Sc., associate professor, Ufa State Petroleum Technological University. 